\title{
Nonlinear site response evidence of K-NET and KiK-net records from the 2011 off the Pacific coast of Tohoku Earthquake
}

\author{
Luis Fabián Bonilla ${ }^{1}$, Kenichi Tsuda ${ }^{2}$, Nelson Pulido $^{3}$, Julie Régnier $^{4}$, and Aurore Laurendeau ${ }^{5}$ \\ ${ }^{1}$ Université Paris-Est, IFSTTAR, France \\ ${ }^{2}$ Shimizu Corporation, Tokyo, Japan \\ ${ }^{3}$ National Research Institute for Earth Science and Disaster Prevention, Tsukuba, Japan \\ ${ }^{4}$ CETE-Méditerranée, Nice, France \\ ${ }^{5}$ ISTERRE, Grenoble, France
}

(Received April 7, 2011; Revised May 25, 2011; Accepted June 8, 2011; Online published September 27, 2011)

\begin{abstract}
We analyzed the acceleration time histories recorded by the K-NET and KiK-net stations of the $M_{\mathrm{w}} 9$ Tohoku Earthquake in order to investigate site response issues related to near-source effects. Time-frequency analysis of K-NET stations in the Miyagi prefecture, closest to the rupture area, show that sites having a $V_{s 30}<$ $400 \mathrm{~m} / \mathrm{s}$ present a combination of deamplification at frequencies higher than 5 to $10 \mathrm{~Hz}$ and cyclic mobility (high acceleration peaks riding over a low frequency carrier). This suggests strong nonlinear site response at these stations. Furthermore, using KiK-net data we are able to compute borehole transfer functions from the mainshock and events having small PGA values from the local dataset. The ratio between weak-motion and strong-motion borehole transfer functions constitutes an indicator of nonlinear site response. This ratio reveals strong dependence on $V_{s 30}$ and shows that widespread nonlinear behavior took place during this large earthquake. Key words: Site response, cyclic mobility, Tohoku Earthquake, K-NET, KiK-net.
\end{abstract}

\section{Introduction}

On the afternoon of March 11th, 2011, an earthquake of magnitude $M_{\mathrm{w}} 9$ occurred off the Pacific coast of Tohoku, Japan (Japan Meteorological Agency, JMA hereafter, 2011). This event is one of the largest earthquakes in the world that has been well recorded in the near vicinity of the source (NIED, 2011). The estimated fault plane is $500 \mathrm{~km}$ along strike in the northeastern part of Japanese mainland and $200 \mathrm{~km}$ along dip (Simons et al., 2011). This event brought devastating damages especially by the tsunami that took place after the mainshock. Yet, the recorded ground motions were also very large. One site recorded a JMA intensity value of 7 (maximum value of this scale) and 28 sites recorded values of 6+ (JMA, 2011). The observed PGA values from K-NET and KiK-net also showed large accelerations for many sites (19 sites showed PGA larger than $1 \mathrm{~g}$ ) and strong motion duration longer than $80 \mathrm{~s}$ (time interval between $5 \%$ and $95 \%$ of the Arias intensity). This event produced a wealth of data showing different types of nonlinear soil behavior, going from traditional high frequency deamplification to liquefaction. These phenomena could be seen on the records of sites at soft soils over a large area along the fault's rupture including Miyagi, Chiba and Tokyo prefectures. For example, Fujikawa (2011) reported that boil sand or liquefaction could be seen for some sites located on soft soil close to Tokyo.

Copyright (C) The Society of Geomagnetism and Earth, Planetary and Space Sciences (SGEPSS); The Seismological Society of Japan; The Volcanological Society of Japan; The Geodetic Society of Japan; The Japanese Society for Planetary Sciences; TERRAPUB.

doi:10.5047/eps.2011.06.012
This study shows a preliminary analysis of the recorded data from the $M_{\mathrm{w}} 9$ Tohoku Earthquake by the K-NET and KiK-net stations to infer nonlinear effects. We first perform time-frequency analysis of the K-NET Miyagi stations, which are the closest to the rupture area, to assess the effect of strong nonlinear effects (cyclic mobility and liquefaction) on the recorded ground motion. Secondly, we assess the mean soil behavior using the KiK-net stations by computing borehole transfer functions (Fourier spectral ratios between the surface and downhole receivers) using weak-motion and strong-motion data, respectively.

\section{Data and Analysis}

The $M_{\mathrm{w}} 9$ Tohoku Earthquake is one of the largest events that has been well recorded in the near-field by numerous stations at the surface (e.g. K-NET and KiK-net) and in boreholes (KiK-net). Figure 1(a) shows the K-NET stations located in the Miyagi prefecture, around $40-50 \mathrm{~km}$ from the fault's rupture. This figure also points the variability of the ground motion, which is correlated by the $V_{s 30}$ beneath each station. We can observe that several stations located on stiff soil $\left(V_{s 30}>400 \mathrm{~m} / \mathrm{s}\right)$ recorded larger PGA values compared to softer sites. This might be already an indication of nonlinear soil behavior. Indeed, nonlinear soil response is usually characterized by a deamplification of the ground motion at high frequencies as well as a shift of the energy toward low frequencies (Beresnev and Wen, 1996). This can be seen on the transfer function. One station, MYG011, is located on rock $\left(V_{s 30} \approx 1400 \mathrm{~m} / \mathrm{s}\right)$. This station has an almost flat earthquake $H / V$ spectral amplitude (not shown here) indicating that it is a good reference 
(a)

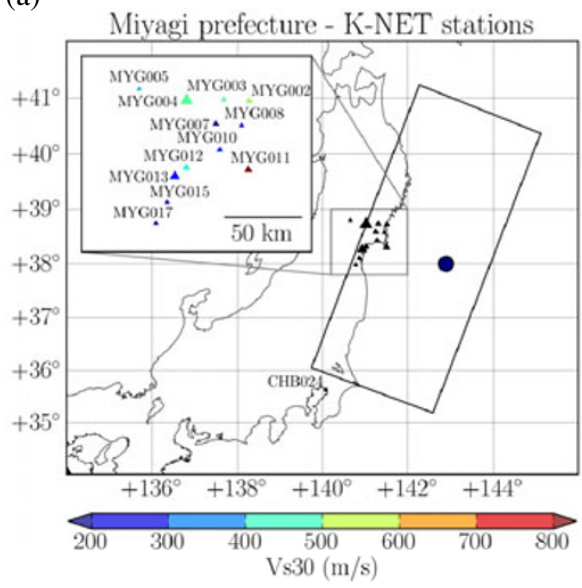

(b)

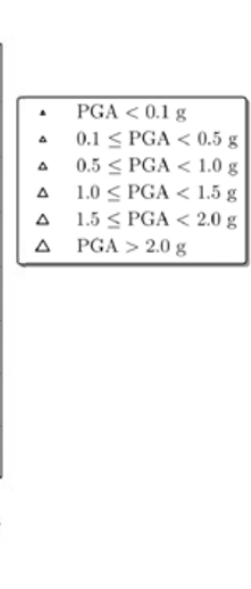

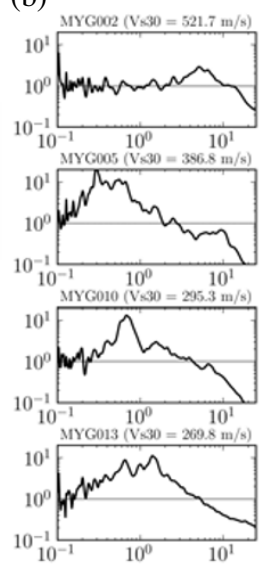
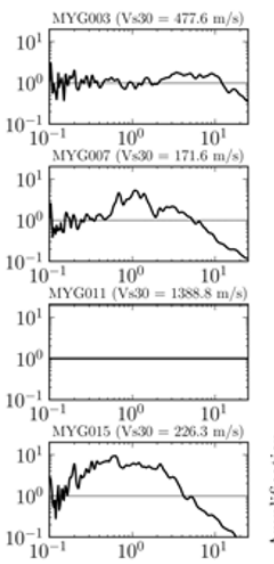
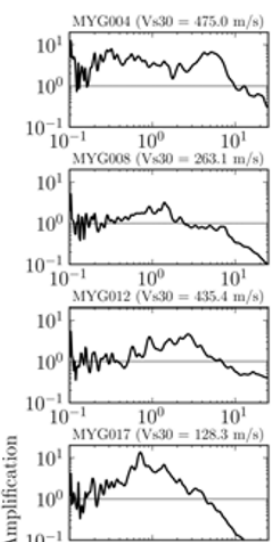

Fig. 1. (a) K-NET stations at the Miyagi prefecture. The black dot represents the epicenter of the mainshock and the rectangle represents the projection of the fault plane on the surface (Simons et al., 2011). The color of stations is related to the $V_{s 30}$ of each site and the size is related to the PGA level. Station CHB024 in Chiba, near Tokyo, is also shown. (b) Fourier spectral ratios (geometric mean of horizontal components) of Miyagi stations with respect to MYG011, which is considered the reference site $\left(V_{s 30}=1400 \mathrm{~m} / \mathrm{s}\right)$. Note the strong deamplification at high frequencies (between 5 and $10 \mathrm{~Hz}$ ) for sites having $V_{s 30}$ below $400 \mathrm{~m} / \mathrm{s}$. Furthermore, the amplification at low frequencies (less than $1 \mathrm{~Hz}$ ) is quite large.

(a)

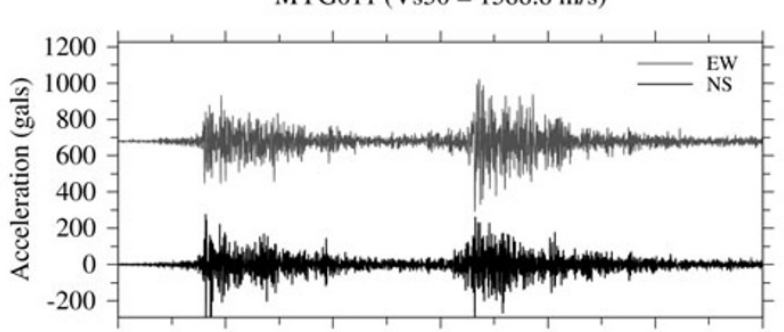

ESD in horizontal plane (S-transform)

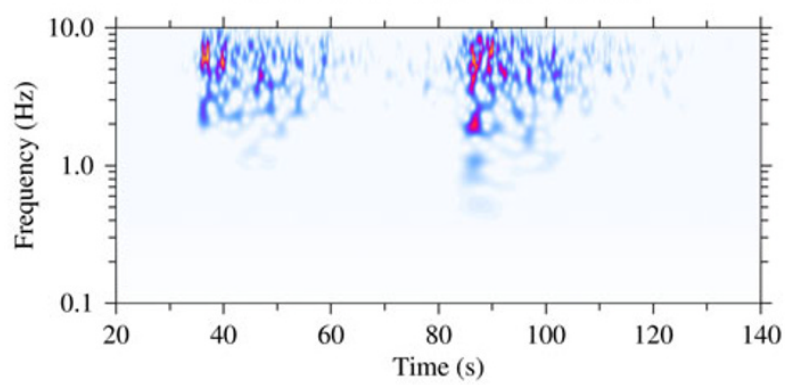

(b)

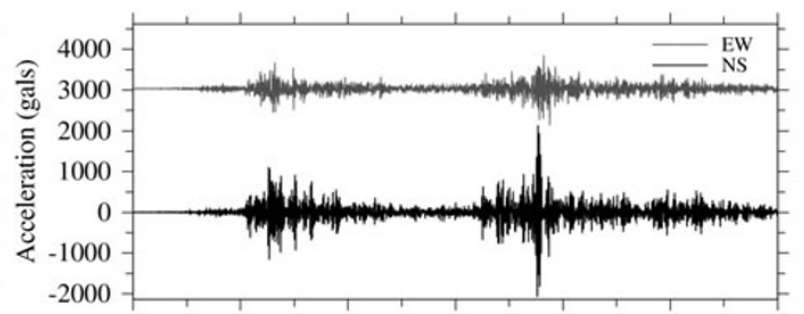

ESD in horizontal plane (S-transform)

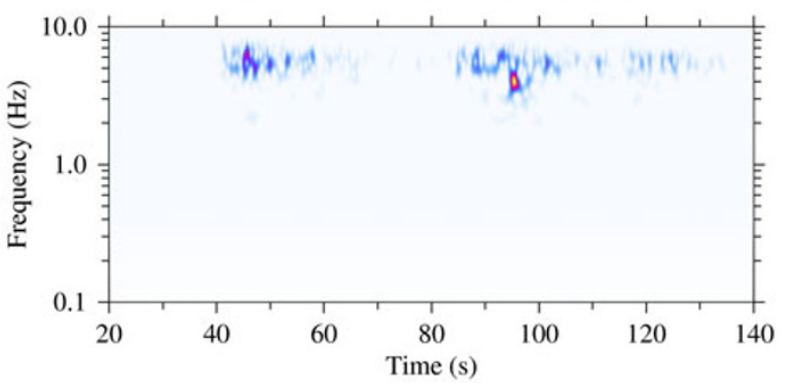

Fig. 2. Time-frequency analysis of the energy spectral density (ESD) of rock (a) and stiff soil sites (b). The former presents a broadband spectral content up to $10 \mathrm{~Hz}$, whereas the latter shows an energy content up to $8 \mathrm{~Hz}$. Note the energy burst at $2 \mathrm{~Hz}$ for MYG011 and at $4 \mathrm{~Hz}$ for MYG004 during the rupture of the second event in both stations.

site, and making possible to compute site-to-reference spectral ratios (Borcherdt, 1970). Figure 1(b) shows the relative amplifications (geometric mean of both horizontal components) of all Miyagi stations with respect to MYG011. One can observe a strong deamplification of the ground motion above 5 to $8 \mathrm{~Hz}$ for stations having $V_{s 30}<400 \mathrm{~m} / \mathrm{s}$. Furthermore, a strong amplification is seen at frequencies lower than 1-2 Hz. Yet, traditional spectral ratios are just an approximation given the close distance to the fault for all sites. Thus, the low frequency amplification may also contain near-source effects, and a linear deconvolution between the source, path, and site effects is difficult in this case. Nonetheless, these results already show an empirical evidence of nonlinear soil response over a relatively large area.

In addition, some K-NET stations, in the vicinity of the Miyagi prefecture and located on soft to relatively stiff soil $\left(200<V_{s 30}<400 \mathrm{~m} / \mathrm{s}\right)$ according to NEHRP site classification (1994), showed large acceleration peak values riding over a low frequency carrier. This has already been shown by Iai et al. (1995), Archuleta (1998), and Bonilla et al. (2005) as an indicator of soil nonlinearity known as cyclic mobility. Laboratory studies show that the physical mechanism that produces such phenomenon is the dilatant nature of cohesionless soils, which introduces the partial recovery of the shear strength under cyclic loads. This re- 
(a)

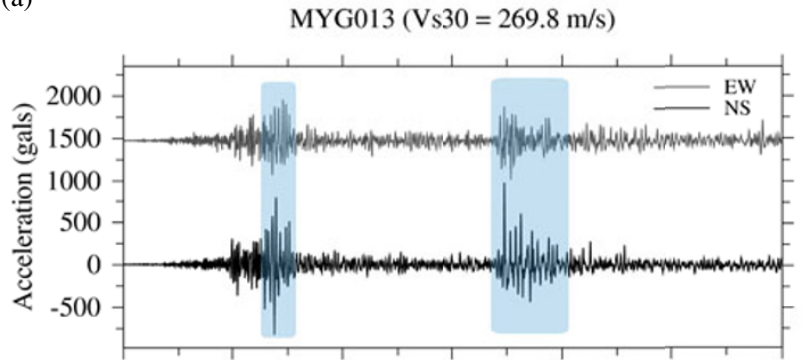

ESD in horizontal plane (S-transform)

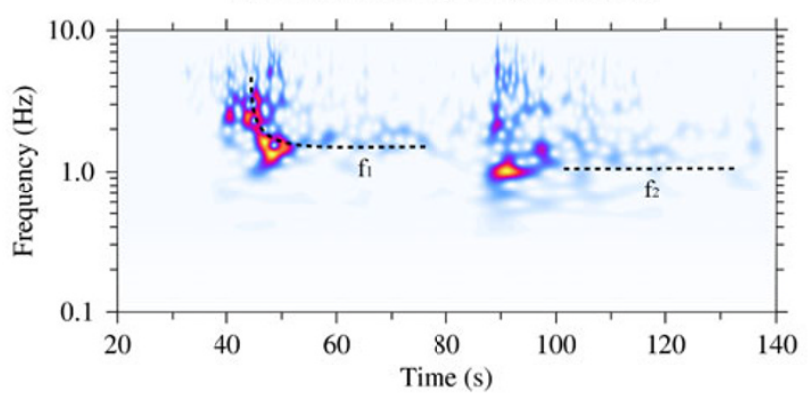

(b)

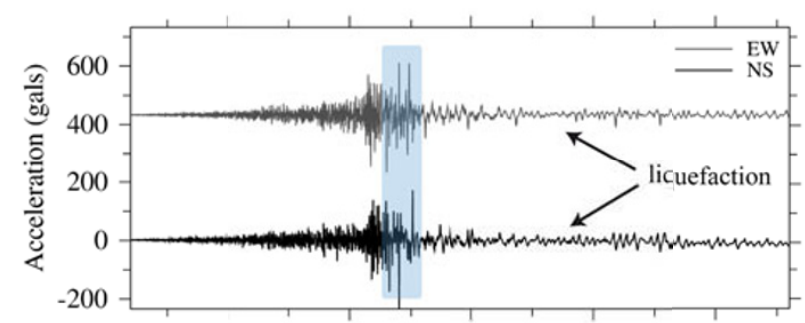

ESD in horizontal plane (S-transform)

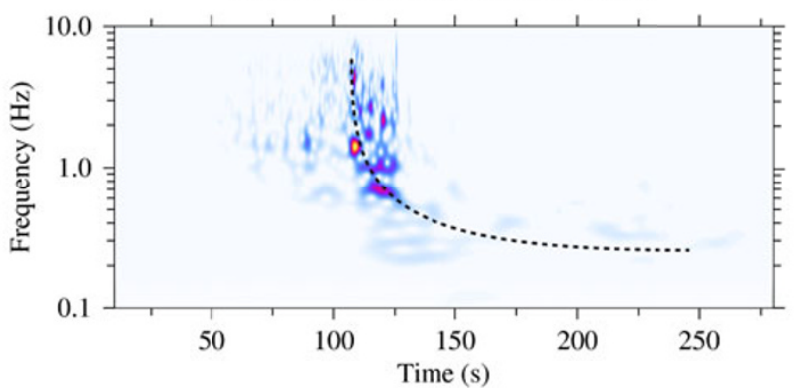

Fig. 3. Time-frequency analysis of the energy spectral density (ESD) of two medium soil sites. (a) Station MYG013 presents acceleration peaks (shaded areas in top panel) typical of cyclic mobility. Concomitantly, there is a shift of energy to lower frequencies after each event's rupture (dashed lines in bottom panel $\mathrm{f}_{2}<\mathrm{f}_{1}$ ). (b) Station CHB024 shows only one event, and the signals go through a strong cyclic mobility (shaded area in top panel) and liquefaction. In addition, note the high frequency missing above $0.5 \mathrm{~Hz}$ after $125 \mathrm{~s}$ in the ESD diagram of this station (dashed line in bottom panel).

covery translates into the ability to produce large deformations followed by large and spiky shear stresses. The spikes observed in the acceleration records are directly related to these periods of dilatancy and generation of pore pressure. In this case, the large values of recorded ground motion are a combination of near-fault and nonlinear site response effects involving fluid mobilization.

In order to see these spectral changes in time, we perform time-frequency analysis of three K-NET stations using the S-transform (Stockwell, 1996). The S-transform allows computing high resolution energy spectral density (ESD) as a function of time. Both components of the horizontal motion are combined into a complex plane before computing the S-transform. In what follows, all figures show the normalized ESD with respect to its maximum value. Figure 2(a) shows the normalized ESD of the rock station, MYG011. One can see that the energy is distributed over all frequencies, up to $10 \mathrm{~Hz}$, for the whole record. Interestingly, at the beginning of the rupture of the second event, a peak of energy is visible at $2 \mathrm{~Hz}$. Conversely, station MYG004 (Fig. 2(b)), which recorded the largest PGA (2.7 $\mathrm{g}$ in the NS component), the peak and the related energy is around $4 \mathrm{~Hz}$, and no energy is seen above $8 \mathrm{~Hz}$. This has already been observed in Fig. 1(b), but with the help of the S-transform, we also see that the deamplification of the ground motion above $8 \mathrm{~Hz}$ lasts practically during the total duration of the record. Yet, more research is needed to elucidate whether these bursts of energy are source or site related.

Figure 3(a) shows the ESD of station MYG013 located on a relative medium soil $\left(V_{s 30}=270 \mathrm{~m} / \mathrm{s}\right)$. The acceleration time histories present high frequency spikes riding over a low frequency carrier, which indicates soil cyclic mobility
(Iai et al., 1995; Archuleta, 1998; Bonilla et al., 2005). The presence of cyclic mobility implies fluid mobilization in the soil, but not necessarily liquefaction. One characteristic of this type of signals is the large accelerations (between 0.5 and $1 \mathrm{~g}$ ) lasting for several seconds. This station shows that cyclic mobility was produced during the two events, around $50 \mathrm{~s}$ for the first and between 90 and $105 \mathrm{~s}$ for the second (shaded areas in top panel of Fig. 3(a)). Furthermore, the S-transform shows frequency shifts of energy to lower frequencies during each event (dashed lines in bottom panel of Fig. 3(a)). Another striking signal corresponds to the records at station CHB024, in Chiba near Tokyo, located at $40 \mathrm{~km}$ from the fault's rupture and shown in Fig. 3(b). This record has only one wave train unlike the other stations in Miyagi prefecture, which is also shown by Simons et al. (2011) for records in the southern part of the fault. In addition, around $120 \mathrm{~s}$, there is the characteristic waveform related to cyclic mobility as station MYG013 (shaded area in top panel of Fig. 3(b)). However, after around $125 \mathrm{~s}$, most energy for frequencies higher than $0.5 \mathrm{~Hz}$ is missing (dashed line in bottom panel of Fig. 3(b)). Moreover, according to a field survey by Chiba University (Sekiguchi and Nakai, 2011), liquefaction was observed very close to the location of the K-NET station (CHB024), as well as in the surrounding areas in the Mihama-ward, Chiba city.

The second part of this preliminary analysis is the study of the borehole transfer functions using the KiK-net stations. We selected 73 sites for this study for which the recorded PGA at the surface (Euclidean norm of the horizontal components) of the $M_{\mathrm{w}} 9$ Tohoku Earthquake was higher than 50 gals (no criteria was imposed on the shear wave velocity at the borehole). Once these sites were identified, their linear response was computed using the data 
(a)

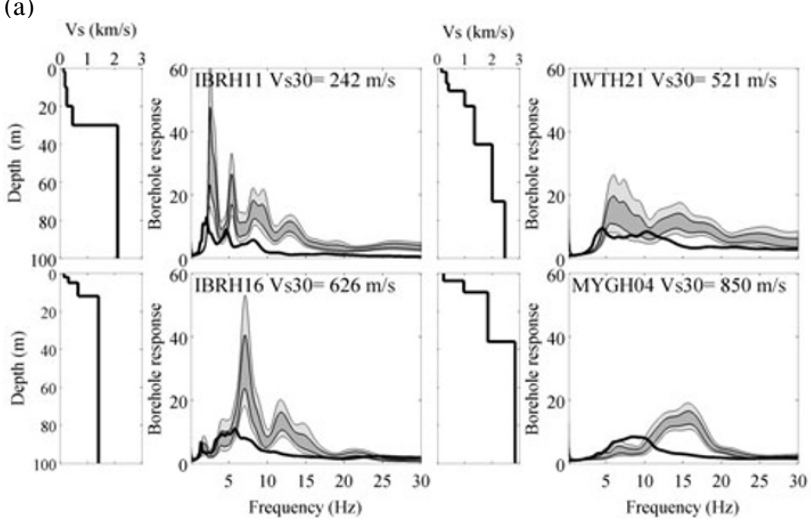

(b)

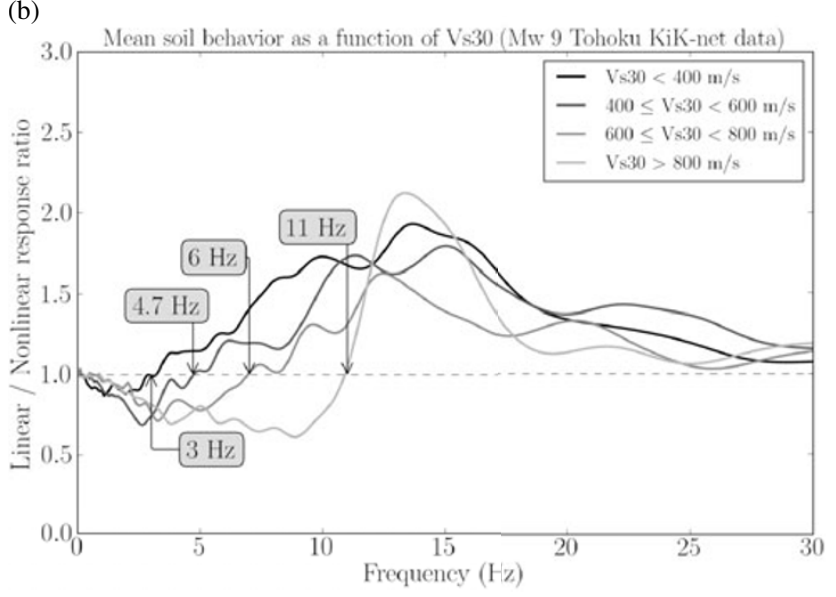

Fig. 4. (a) Example of KiK-net stations where linear borehole response is computed at $68 \%$ (dark gray area) and $95 \%$ (light gray area) confidence limits. Black line represents the nonlinear borehole response computed using the $M_{\mathrm{w}} 9$ Tohoku data. (b) average linear-to-nonlinear borehole response ratios for all $\mathrm{KiK}-$ net sites for different $V_{s 30}$ classes. When this ratio is greater than one means that the soil behaves nonlinear. Note the clear separation among classes and the broadband nonlinear response (3 to $30 \mathrm{~Hz}$ ) for soils having $V_{s 30}<400 \mathrm{~m} / \mathrm{s}$.

recorded from 1998 to 2009 having PGA's at the surface not exceeding 10 gals. Figure 4(a) shows an example of four KiK-net stations having different $V_{s 30}$ values where the linear borehole transfer function is characterized at $68 \%$ (dark gray area) and 95\% (light gray area) confidence limits. The black line shows the nonlinear borehole transfer function computed using the mainshock. One can see that the mainshock is largely deamplified at high frequencies, and a shift of the predominant frequency to lower values. Furthermore, the frequency at which deamplification increases as the station's $V_{s 30}$ increases. For example, station IBRH16 $\left(V_{s 30}=626 \mathrm{~m} / \mathrm{s}\right)$ deamplifies around $7 \mathrm{~Hz}$; whereas station MYGH04 $\left(V_{s 30}=850 \mathrm{~m} / \mathrm{s}\right)$ deamplifies around $12 \mathrm{~Hz}$. In order to see the average nonlinear behavior for all $\mathrm{KiK}$ net stations, we followed the same procedure as Field et al. (1997), who computed the ratio between linear and nonlinear amplification functions. Thus, if this ratio is larger than one, nonlinear behavior is suspected at a given frequency band. Figure 4(b) shows the mean borehole response ratio as a function of $V_{s 30}$. One can clearly see that nonlinear soil effects increase with decreasing $V_{s 30}$ values. This figure indicates a broadband nonlinear behavior for soils having $V_{s 30}$ $<800 \mathrm{~m} / \mathrm{s}$, from $3-6$ to $30 \mathrm{~Hz}$. Another striking result is the presence of nonlinear behavior even at sites having $V_{s 30}$ $>800 \mathrm{~m} / \mathrm{s}$ following NEHRP soil classification. A closer analysis of their velocity profiles shows that the first $10 \mathrm{~m}$ have a shear wave velocity ranging from 200 to $400 \mathrm{~m} / \mathrm{s}$, which may explain these observations. Nonetheless, these are average results only, more studies are needed to assess the uncertainties related to these observations.

\section{Conclusions}

A preliminary analysis of K-NET and KiK-net records from the $M_{\mathrm{w}} 9$ Tohoku Earthquake has been performed. The results show that widespread nonlinear site response took place in several K-NET and KiK-net stations. Some of the K-NET stations show signs of pore pressure effects on dilatant soils. These nonlinear effects produce high acceleration peaks (between 0.2 to $1 \mathrm{~g}$ ) riding a low frequency carrier that lasted several seconds. The analysis of KiK-net stations shows that nonlinear effects correlates well with $V_{s 30}$. The most striking observation is that even sites having $V_{s 30}>800 \mathrm{~m} / \mathrm{s}$ were affected at frequencies higher than $11 \mathrm{~Hz}$. They went probably nonlinear due to the presence of a thin layer of about $10 \mathrm{~m}$ thick with $V_{s}$ between 200 and $400 \mathrm{~m} / \mathrm{s}$. This event, together with its foreshocks and aftershocks, produced an impressive amount of data that still need to be analyzed. Thus, future studies should include foreshock and aftershock data to complete nonlinear soil behavior at KiK-net stations. In addition, we need to study the relation between lithology and velocity profiles beyond $30 \mathrm{~m}$ depth to have a better understanding where nonlinear effects took place. Indeed, this work shows that for sites having $V_{s 30}>800 \mathrm{~m} / \mathrm{s}$, nonlinear effects might be located at shallow depths; but this is not clear for softer soils. Finally, this event shows the need to take into account source, wave propagation and dynamic site characterization in order to better estimate the expected ground motion.

Acknowledgments. We are indebted to the National Research Institute for Earth Science and Disaster Prevention (NIED) in Japan for providing the data for this analysis in spite of all human and technical difficulties they are facing during the earthquake's aftermath. We are also grateful to John Douglas and an anonymous reviewer for their comments that helped to improve this manuscript.

\section{References}

Archuleta, R. J., Direct observation of nonlinear soil response in acceleration time histories, Seismol. Res. Lett., 69, 149, 1998.

Beresnev, I. A. and K. L. Wen, Nonlinear site response-a reality?, Bull. Seismol. Soc. Am., 86, 1964-1978, 1996.

Bonilla, L. F., R. J. Archuleta, and D. Lavallée, Hysteretic and dilatant behavior of cohesionless soils and their effects on nonlinear site response: Field data observations and modeling, Bull. Seismol. Soc. Am., 95, 2373-2395, 2005.

Borcherdt, R. D., Effects of local geology on ground motion near San Francisco Bay, Bull Seismol. Soc. Am., 60, 29-61, 1970.

Field, E. H., P. A. Johnson, I. A. Beresnev, and Y. Zeng, Nonlinear groundmotion amplification by sediments during the 1994 Northridge earthquake, Nature, 390, 599-602, 1997.

Fujikawa, S., Personal communication, 2011.

Iai, S., T. Morita, T. Kameoka, Y. Matsunaga, and K. Abiko, Response of a dense sand deposit during 1993 Kushiro-Oki Earthquake, Soils and Foundations, 35, 115-131, 1995.

Japan Meteorological Agency, http://www.jma.go.jp/jma/en/ 2011_Earthquake.html, 2011.

National Earthquake Hazards Reduction Program (NEHRP), Recommended Provisions for Seismic Regulations for New Buildings, 290 pp, 
Federal Emergency Management Agency Report FEMA 222A, Washington, D.C., 1994.

National Research Institute for Earth Science and Disaster Prevention (NIED), http://www3.kyoshin.bosai. go.jp/k-net/topics/TohokuTaiheiyo_20110311/nied_ kyoshin2e.pdf, 2011.

Sekiguchi T. and S. Nakai S, Damage investigation around Chibacity for Tohoku Taiheiyo earthquake by Nakai Laboratory, Chiba University, http://pollux.tu.chiba-u.jp/ TouhokuEQ2011/Chiba-Mihamaku_110325.pdf, 2011.

Simons, M., S. E. Minson, A. Sladen, F. Ortega, J. Jiang, S. E. Owen, L.
Meng, J.-P. Ampuero, S. Wei, R. Chu, D. V. Helmberger, H. Kanamori, E. Hetland, A. W. Moore, and F. H. Webb, The 2011 magnitude 9.0 Tohoku-Oki Earthquake: Mosaicking the megathrust from seconds to centuries, Science, doi:10.1126 science.1206731, 2011.

Stockwell, R. G., L. Mansinha, and R. P. Lowe, Localization of the complex spectrum: the $\mathrm{S}$ transform, IEEE Trans. Signal Processing, 44, 998-1001, 1996.

L. F. Bonilla (e-mail: fabian.bonilla@ifsttar.fr), K. Tsuda, N. Pulido, J. Régnier, and A. Laurendeau 